\title{
COVID-19: Una mirada desde la virología
}

\author{
COVID-19: A look from virology
}

La emergencia de un nuevo virus está desafiando a la humanidad en muchos sentidos. Estamos acostumbrados a considerar a los virus según los sistemas que comprometen y sindromes que provocan. Tendremos que clasificarlos como se hace en la actualidad, por su estructura: ácido nucleico ADNo ARN, presencia de envoltura (manto) y forma de replicar su ácido nucleico (clasificación de Baltimore), porque su permanencia como especie depende de ello. En efecto, los virus ADN tienen de algún modo la ventaja de ingresar al núcleo de la célula y aprovechar la maquinaria metabólica para replicar su ADN u ocultarse en su genoma. Los virus ARN, deben portar o codificar una ARN polimerasa ARN dependiente para multiplicar su genoma, pues esa función no existe en la naturaleza; afortunadamente para los virus, no para el hospedero humano, esta ARN polimerasa comete errores frecuentemente y permite la generación de mutantes de distintas consecuencias evolutivas. Por otro lado, la presencia de un manto lipoproteico hace al virus inestable en el medio ambiente y obliga al virus a usar mecanismos de transmisión directos para alcanzar nuevos hospederos ${ }^{1,2}$.

Pues bien, el nuevo virus emergente el 2019 que se denomina virus del Sindrome Agudo Respiratorio Severo (SARS-CoV-2), es un virus ARN, con manto, que se transmite por vía respiratoria. De la familia Coronaviridae, contiene 7 especies que afectan al ser humano provocando infecciones respiratorias altas, tipo resfrío común, pero tres de ellas son capaces de producir además infecciones respiratorias bajas graves: SARS CoV (2002-2004), MERS (2013 hasta hoy) y SARS-CoV-2 (2019)². Esta familia contiene virus patógenos para diversos animales, como aves, peces y mamíferos (murciélagos, camellos, cerdos, bovinos, gatos, perros y otras especies que son exóticas). Si bien existen barreras de especies, suelen ocurrir saltos de especies, pero para establecer la capacidad de transmitirse en el nuevo hospedero se requiere de más mutaciones. Entre las virosis respiratorias el mejor ejemplo comparativo lo representa la influenza A, que ha obligado a la OMS a establecer una red mundial para su vigilancia ${ }^{1,2}$.

Se discute si los virus son entidades vivas o muertas. Fuera de las células son completamente inertes, pero si se dan las condiciones ambientales conservan la capacidad de ingresar a células animales, vegetales, bacterias, hongos o virus e iniciar su replicación.

Mirémosles desde el punto de vista ecológico. Ellos son un simple código genético a multiplicarse, alternando entre estados de vida y no vida; se copian a sí mismos como siempre lo han hecho, en su hospedero natural o en otro nuevo: no tienen un plan o deseo. En cantidad son tantos y tan ubicuos que el número de genes virales encontrados en la superficie de un pequeño océano supera ampliamente el número de estrellas que la ciencia astronómica pudiera observar. En la tierra los virus matan más elementos vivos que cualquier otro predador; ellos modulan el balance de especies de ecosistemas tan diversos como el mar abierto y el intestino humano; ellos intervienen en la evolución aportando selección natural y adaptación de genes ${ }^{3,4}$. Se estima que los virus conocidos que afectan al ser humano son alrededor de 263, de un número potencial de virus que lo podrían afectar de 600.000 a $800.000^{5}$.

La historia de las pandemias muestra ejemplos de virus y bacterias que han azotado a la humanidad desde la Antigüedad provocando millones de muertes, tal vez la forma más objetiva de estimar su magnitud. Actualmente, la pandemia de VIH/SIDA ha provocado desde 1981 a la actualidad entre 25 y 35 millones de muertes, mientras que la pandemia de virus influenza A H2N2 de 1957 habría ocasionado 1,1 millón de muertes. La pandemia por el anterior virus $S A R S$ solo produjo 8.098 casos con 9,5\% de letalidad, y fue exitosamente eliminada ${ }^{6,7}$.

En este contexto, hasta hoy día la ciencia y la tecnología solo han logrado erradicar al virus de la 
viruela (1977) y de las poliomielitis 2 (2015) y 3 (2019), usando vacunas vivas atenuadas desarrolladas con tecnología tradicional con décadas de anticipación. Por eso, controlar la pandemia actual es un inmenso desafio para la humanidad'.

El SARS-CoV-2 se transmite por vía aérea por 3 mecanismos: (i) Por contagio directo de persona a persona, por las gotitas de secreciones respiratorias $\geq 5 \mu \mathrm{m}$ que se emiten al respirar, hablar, gritar, toser, estornudar, besar, etc., por uno a dos metros de distancia. Es el mecanismo más importante a nivel individual y colectivo comunitario; (ii) También el estornudo y la tos generan aerosoles de gotas $\leq 5 \mu \mathrm{m}$ que se mantienen en el aire a mayor distancia; (iii) El depósito de las secreciones en el ambiente cercano- manos, ropa, utensilios, paredes, superficies de madera, plástico, metales, etc. - donde el virus sobrevive desde 15 minutos a 4 dias, según las condiciones físicas; en ambientes al aire libre, la dilución en el aire y la irradiación UV solar frustran rápidamente la transmisión. Este potencial mecanismo no juega un rol epidemiológico trascendente, aunque pueda ocurrir en casos anecdóticos ${ }^{1,7}$. Su transmisibilidad, medida por el 'Número de Reproducción' (Ro) se ha determinado entre 2,2 y 3,52.

Todavía no se dispone de vacuna contra COVID-19, pero hay muchos candidatos en desarrollo. La proteina "S" (spike) del SARS-CoV-2 es la principal inductora de anticuerpos neutralizantes que deberían proteger por al menos un año y es el blanco de las estrategias. Hay básicamente ocho modelos de estrategias en desarrollo: virus inactivado o atenuado, vectores virales replicantes y no replicantes, vacunas de ADN o ARN, y las basadas en proteinas, como subunidades o virus símil. Pero, aunque tengan un desarrollo acelerado, antes de producirlas industrialmente deben pasar por las fases clínicas de seguridad, inmunogenicidad y eficacia, para ser licenciadas, lo que suele demorar varios años ${ }^{2,8}$. Para tratamiento específico sólo existe un antiviral con eficacia clínica para casos graves y su impacto epidemiológico es limitado.

La epidemia se inició en diciembre de 2019 en Wuhan, China. Su fuente fue identificada rápidamente como un nuevo Betacoronavirus, del subgénero Sarbecovirus, por análisis genómico y fue relacionado a coronavirus de murciélagos (Rhinolophus bat). Este virus, posiblemente usando como hospedero trampolín un mamífero exótico - el pangolín (Manis javanica) - logró la capacidad de transmitirse entre humanos gracias a una mutación en la glicoproteína de superficie $S$ (spike) ${ }^{2}$. La enfermedad caracterizada por fiebre, tos, malestar general y a veces neumonía se denominó COVID-19. Dada su rápida expansión a otros países y continentes la OMS declaró "pandemia" el 11 de marzo de 2020. Gracias a la rápida secuenciación del virus y la difusión de la información científica se implementó en todo el mundo un diagnóstico altamente sensible y específico basado en la reacción de polimerasa en cadena (PCR), que ha permitido por primera vez en la historia, hacer un seguimiento de la pandemia desde su inicio.

En estas circunstancias se estima que la única forma de controlar la pandemia, mientras no se disponga de vacunas, consiste en instaurar medidas de contención comunitaria no farmacológicas ${ }^{9}$. Se ha calculado que para un Ro de 2,3 se requeriría una proporción de contagiados (Pc) de 57\% de la población, para lograr una inmunidad de rebaño que detenga la propagación del virus $(P c=1-1 / R o)$. No obstante, el aparente rápido avance de la pandemia, su contagiosidad es baja y al 7 de septiembre de 2020, se han confirmado 27.032.617 casos con 881.464 muertes ${ }^{10}$. Para una población mundial de 7.700 millones, recién se ha contagiado el 0,35\% de la población; si lo multiplicamos por 10 para abarcar los casos asintomáticos y los no diagnosticados, se iría recién en 3,5\%. Las pandemias de influenza comprometen más del $30 \%$ de los habitantes ${ }^{2,6}$.

Las estrategias de contención se conocen y las estamos experimentando personalmente. Se menciona en primera línea el uso de mascarillas, el distanciamiento fisico y el frecuente lavado de manos; simultáneamente es indispensable diagnosticar los casos clínicos usando PCR y estudiar a sus contactos estrechos para proceder al aislamiento o confinamiento, según las circunstancias. Además se recomiendan medidas restrictivas de la movilidad, suspensión de cualquier actividad que aglomere gente (guarderías, salas cuna, colegios, universidades; deporte, espectáculos, comercio, etc.), llegando a decretarse cuarentenas territoriales y cierre de frontera por aire mar y tierra, ${ }^{9,10}$.

El curso de la pandemia tiene distinta forma y temporalidad y no sabemos si se debe a su evolución 
natural o por la efectividad de la contención en curso, lo que hace incierto su futuro, tanto en intensidad como en duración ${ }^{11}$. Al menos en Chile la sorprendente desaparición de los virus respiratorios de invierno muestra que la contención se ha llevado en forma adecuada (Figura 1).

Sin embargo, hay factores virales que impiden una mayor eficacia de las medidas adoptadas con distinto grado de cumplimiento en el mundo (Figura 2). En primer lugar el virus se transmite desde tres días antes de presentar síntomas; luego, se estima que $80 \%$ de los individuos contagiados no presentan sintomas, pero igualmente son transmisores ${ }^{2}$.

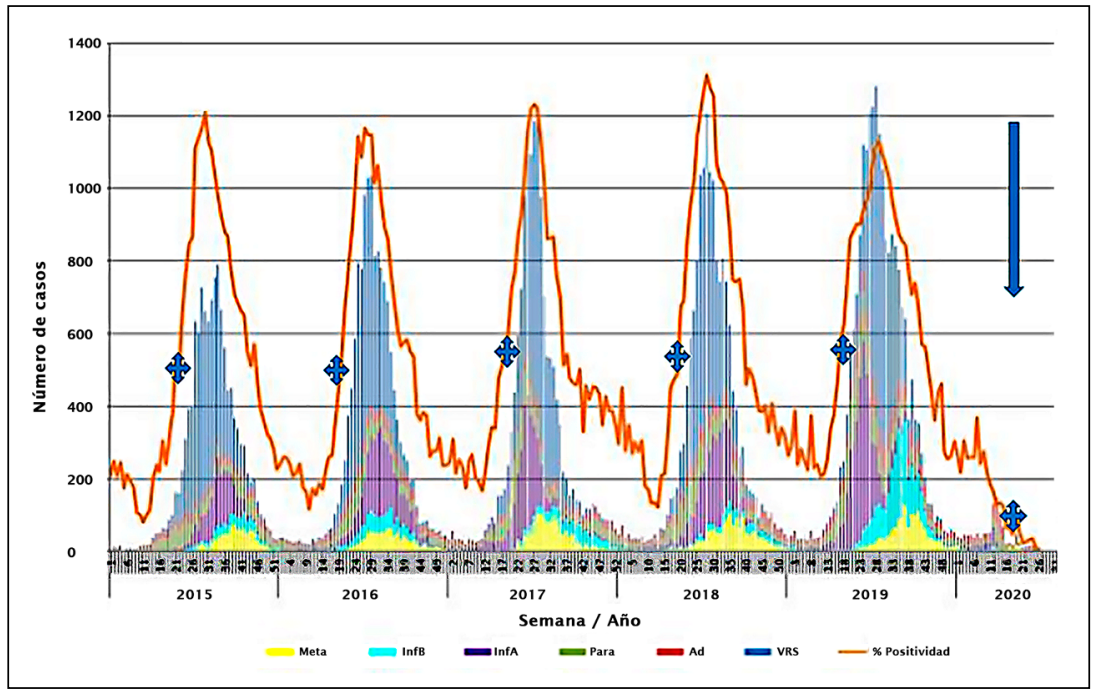

Figura 1. Vigilancia de virus respiratorios. Semana Epidemiológica 28, 2020. Chile. La flecha en la derecha del gráfico muestra la influencia de medidas de contención. (Fuente: ispch. $\mathrm{cl}$ /virus respiratorios).

\section{Americas}

$14,193,356$

confirmed cases

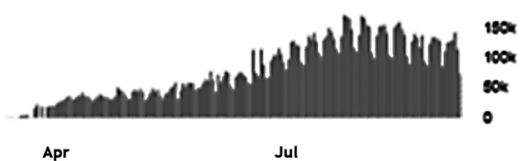

\section{Europe}

$4,536,086$

confirmed cases

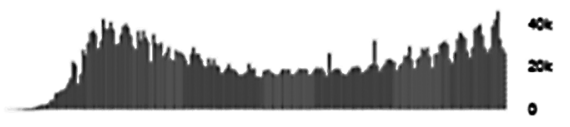

Apr

Jul

\section{South-East Asia}

\section{$4,869,112$}

confirmed cases

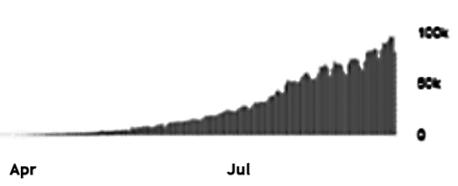

Africa

$1,092,149$

confirmed cases

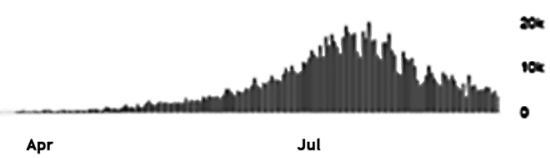

Western Pacific

Eastern Mediterranean

522,080

2,023,392

confirmed cases
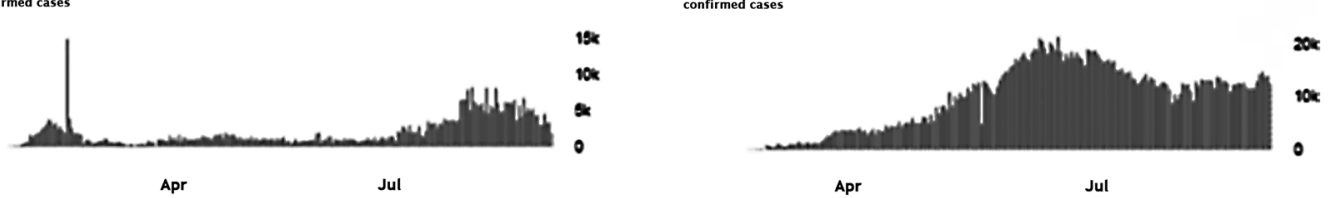

Apr

Jul

Figura 2. Evolución de la COVID-19 en diferentes continentes al 8/9/2020. Fuente referencia 11: covid19.who.int. 

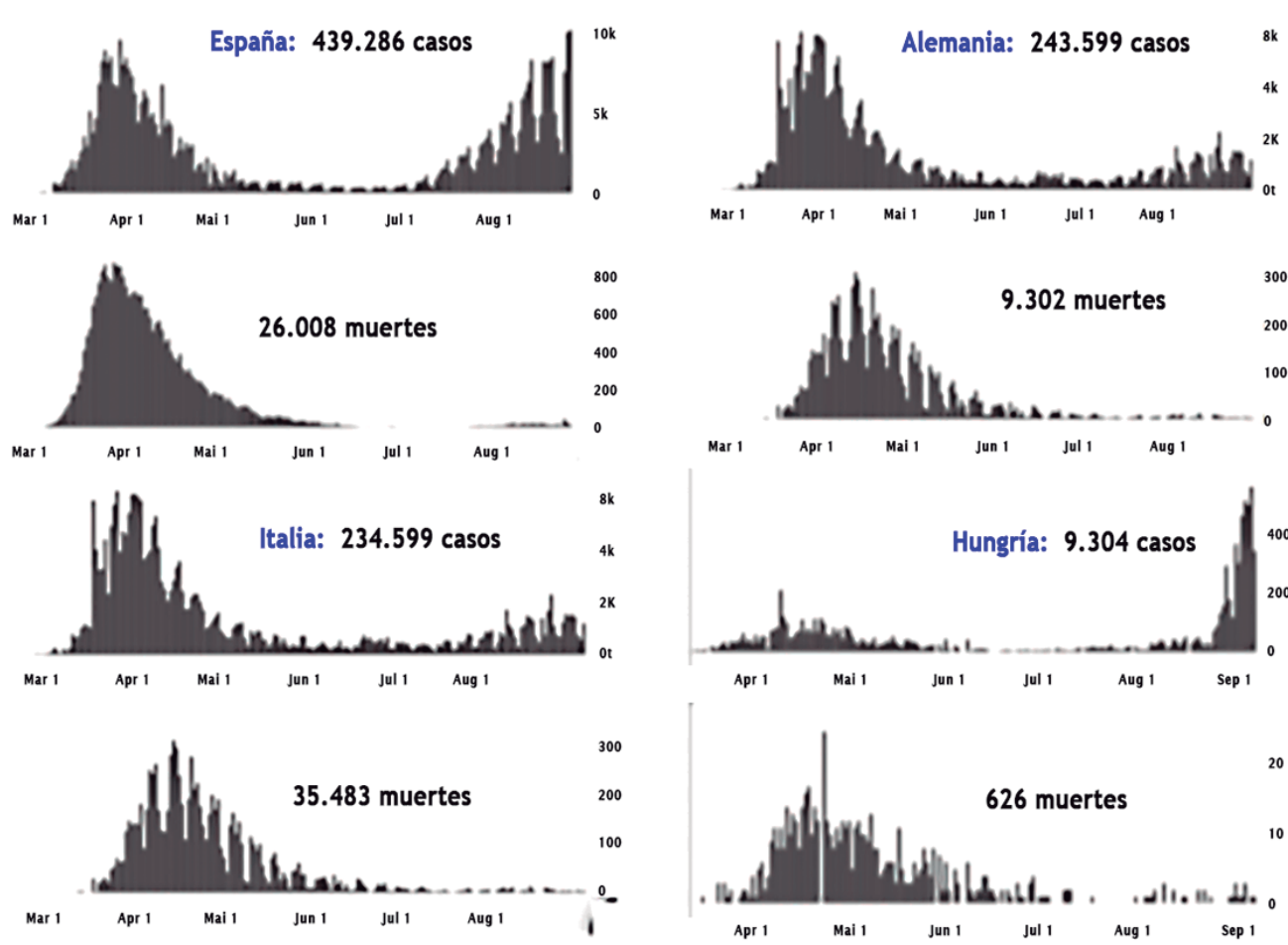

Apr 1 Mai 1 Jun 1 Jul 1 Aug $1 \quad$ Sep 1

Figura 3. Evolución de la pandemia por SARS-COV-2 en España, Alemania, Italia y Hungría. Se muestran primeras y segundas olas de contagios (Fuente: Referencia 11: covid19.who.int).

Con este tipo de transmisión respiratoria... ¿cómo se puede evitar el contagio? La trazabilidad de los casos activos y sus contactos cercanos... ¿no llegará siempre tarde? Los casos activos pre-sintomáticos y los asintomáticos... ¿cómo pueden evitar contagiar en espacios cerrados? Mientras no se alcance una inmunidad de rebaño... habrá rebrotes, ¿serán más suaves o más intensos? La información del momento muestra que los rebrotes provocan mucho menos muertes y los invito a pensar: a) porque ya fallecieron los más débiles; b) porque cambió el virus; c) porque ahora hay mejor manejo de la pandemia; d) porque ahora se contagia gente más joven; e) lo sabremos en el futuro (Figura 3). Al parecer al virus no le interesa ser más transmisible, pues va cumpliendo su meta de mantenerse como especie.

En la patogenia de las infecciones se estima que intervienen factores derivados del agente (coronavirus), el hospedero (Homo sapiens) y el ambiente, los cuales están en permanente cambio. Ya se conoce que si bien el SARS-CoV-2 varió por mutación en la proteína $S$ y que tiene varios hospederos animales, no es tan frecuente su variabilidad, comparada con los virus influenza A de 1957. En este tiempo el ambiente podría haber influido en la mayor urbanización que tiende a aglomerar gente en edificios, oficinas, medios de transporte y otros; en 1960 el 68\% de la población era urbana, versus el $89 \%$ en 2017. ¿Pero, en qué ha variado el ser humano, para entender este colapso social y económico de la magnitud que estamos viviendo? El historiador Yuval Noath Harari plantea en su libro Homo Deus que el Sapiens -habiendo superado los grandes problemas mundiales de las guerras, el hambre y las pestes- se encuentra hoy abocado a los avances de la biotecnología y la informática y orientado a incrementar su poder y longevidad, dominando al mundo. ¿Estará ahora agotando todos los recursos disponibles para derrotar a un mísero virus?

En las condiciones actuales -mientras no se desarrollen vacunas eficientes- tendremos que seguir individual y colectivamente adaptando nuestro sistema de vida al curso de la pandemia por el SARS-CoV-2. Es decir, seguir usando mascarillas, distanciamiento físico, lavado frecuente de manos, evitando aglomeraciones y maximizando las formas de detección de casos y contactos. Y deberíamos 
someternos a las restricciones que las autoridades sanitarias y políticas consideren: ¿es un deber ético? Porque aparentemente tendremos que seguir cuidando a las personas de mayor riesgo de gravedad por mucho tiempo más.

Dr. Luis Fidel Avendaño Carvajal ${ }^{1}$

${ }^{1}$ Profesor Titular. Programa de Virología. ICBM. Facultad de Medicina. Universidad de Chile. Miembro Honorario. Academia Chilena de Medicina. Instituto de Chile.

Email:lavendan@uchile.cl

\section{Bibliografía}

1.- AVENDAÑO LF, FERRÉS M, LUCHSINGER V, SPENCER E. Virología Clínica. $2^{\mathrm{a}}$ Ed. Santiago: "Ed Mediterráneo", 2018.

2.- DHAMA K, KHAN S, TIWARI R, SIRCAR S, BHAT S, MALIK YS, et al. Coronavirus Disease 2019-COVID 2019. Clin Microbiol Rev 2020; 33:e00028-20. Disponible en: https://doi.org/10.1128/ CMR.00028-20.

3.- DE WIT E, VAN DOREMALEN N, FALZARANO D, MUNSTER VJ. SARS and MERS: recent insight into emerging coronaviruses. Nat Rev Microbiol 2016;14 (8): 523-34.

4.- THE ECONOMIST TODAY. The viral universe. Viruses have big impacts in ecology and evolution as well as in human health. Editorial. Daily newsletter August 20, 2020.

5.- CARROLL D, DASZAK, P, WOLFE N, GAO GF, MOREL CM, MORZARIA S, et al. The Global Virome Project. Science 2018; 359: 874. doi: 10.1126/ science.aap7463.
6.- LEPAM N. Visualizing the History of Pandemics. Healthcare 2020. Disponible en: https:// www.visualcapitalislist.com/history-of-pandemics-deadliest/.

7.- PEIRIS MJS, POON LLM. Coronaviruses and Toroviruses. En: Zuckerman AJ, Batnavala JE, Schoub BD, Griffiths PD, Mortimer P. Principles and practice of Clinical Virology $6^{\text {a }}$ Ed. West Sussex. John Wiley \& Sons Ltd. 2009.

8.- LURIE N, SAVILLE M, HATCHETT R, HALTON J. Developing Covid-19 vaccines at pandemic speed. NEJM 2020; 382: 1969-73. doi: 10.1056/NEJMp2005630.

9.- FERGUSON NM, LAYDON D, NEDJATI-GILANI G, IMAI N, AINSLIE K, BAGUELIN M, et al. Impact of non-pharmaceutical intervention (NPIs) to reduce COVID-19 mortality and healthcare demand. 2020. doi: https://doi.org/10.25561/77482.

10.- PRATHER KE, WANG CC, SCHOOLEY RT. Reducing trasnmission of SARS.CoV-2. Science 2020: 368 (6498): 1422-24. doi: 10.1126/science.abc6197.

11.- WHO Coronavirus Disease (COVID-19) Dahsboard. covid19.who.int 